\title{
Papiloma invertido vesical con recidiva en uretra prostática
}

\author{
B. Coronel Sánchez, R. Ferrero Doria, F. Moreno Pérez, F. García Víctor, M. Gasso Matoses, \\ E. Díaz Calleja
}

Servicio de Urología. Hospital Francesc de Borja. Gandia. Valencia.

Actas Urol Esp 2005; 29 (10): 989-992

\section{RESUMEN}

PAPILOMA INVERTIDO VESICAL CON RECIDIVA EN URETRA PROSTÁTICA

El papiloma invertido del tracto urinario es una lesión generalmente solitaria y con poca tasa de recidivas.

Su comportamiento es desconocido, no estando aclarado su potencial de recidiva y/o progresión.

Presentamos un caso de papiloma invertido vesical con recidiva en uretra prostática a los cuatro años de seguimiento. Revisamos aspectos etiológicos, clínicos, diagnósticos y de tratamiento así como la discusión actual sobre su potencial de malignización.

Palabras clave: Papiloma invertido. Recidiva. Potencial maligno.

\section{ABSTRACT \\ INVERTED PAPILLOMA OF THE BLADDER WITH RECURRENCE IN PROSTATIC URETHRA}

Urothelial inverted papilloma is usually a solitary lesion with rare recurrences.

Its behaviour is unclear, its potential for recurrence or progression is not well-known.

We present a case of inverted papilloma of the bladder with recurrence in prostatic urethra after four years of follow-up. We review etiology, clinical presentation, diagnose, treatment and the present discussion about its malignancy ability.

Keywords: Inverted papilloma. Recurrence. Malignancy potencial.

$\mathrm{E}^{\prime}$ papiloma invertido es una lesión poco frecuente del tracto urinario. Su frecuencia se estima en un $2,2 \%$ de todas las lesiones tumorales de la vía urinaria ${ }^{1-9}$. La localización más habitual es en cuello $(44,7 \%)$ y trígono $(36,8 \%)$ vesicales $^{6,9,10}$, aunque también puede aparecer en otras zonas del tracto urinario como pieloureteral $(7 \%)$, ureteral $(12 \%)$ y con mucha menor frecuencia en uretra prostática ( $3 \%)^{1,2,5-7,9,11}$.

Clínica y macroscópicamente se confunde con facilidad con el carcinoma urotelial aunque debido a sus específicas características histológicas, es considerado como una entidad propia ${ }^{6,8}$.

Histopatológicamente todavía existe hoy en día controversia acerca de su relación con el carcinoma del tracto urinario $3,4,9,12-15$, hecho al que contribuye el que la mayoría de publicaciones existentes correspondan a series cortas de pacientes, siendo quizá necesarios estudios con mayor tiempo de seguimiento y número de casos.

Presentamos un nuevo de caso de papiloma invertido vesical con recidiva en uretra prostática a los 4 años.

\section{CASO CLINICO}

Paciente varón de 61 años en la actualidad, fumador de 20 cigarrillos/día, sin otros antecedentes de interés, es remitido a nuestra consulta en Febrero del año 2000 por cuadro de hematuria total monosintomática, esporádica y autolimitada de inicio aproximado dos meses antes. En la anamnesis refiere sintomatología prostática leve, de predominio obstructivo de varios años de evolución. 
La exploración física es normal. El tacto rectal corresponde a una próstata aumentada de volumen, de consistencia fibroelástica, móvil y sin nódulos palpables compatible con adenoma II/IV.

La analítica sanguínea realizada se encuentra dentro de los parámetros de la normalidad con un PSA de 2,6 ng/ml. La citología urinaria muestra ausencia de células malignas.

Ecográficamente se objetiva normalidad renal, próstata de 30 cc y neoformación sesil de aproximadamente $1 \mathrm{~cm}$ en cara lateral izquierda vesical. En el estudio urográfico practicado (Fig. 1) se confirma el defecto de replección en cara lateral izquierda del cistograma.

Se realizó RTU de la lesión siendo el diagnóstico anatomopatológico de papiloma invertido vesical (Fig. 2). Se observa una proliferación de cordones de células transicionales que parecen invaginarse en la lámina propia y recubiertos en superficie por un epitelio transicional aplanado.

El seguimiento llevado a cabo en nuestro servicio fue similar al de un carcinoma de células transicionales de bajo grado. Realizamos citología urinaria y uretrocistoscopia a los 6 meses, al año y después de forma anual siendo estos controles normales.

En la revisión del cuarto año, el paciente relata empeoramiento significativo de la sintomatología obstructiva sin hematuria asociada, de cuatro meses de evolución, cuadro por el cual no había consultado decidiendo esperar a la visita anual.

En la uretrocistoscopia encontramos una neoformación polipoidea en uretra prostática muy próxima al veru montanum.

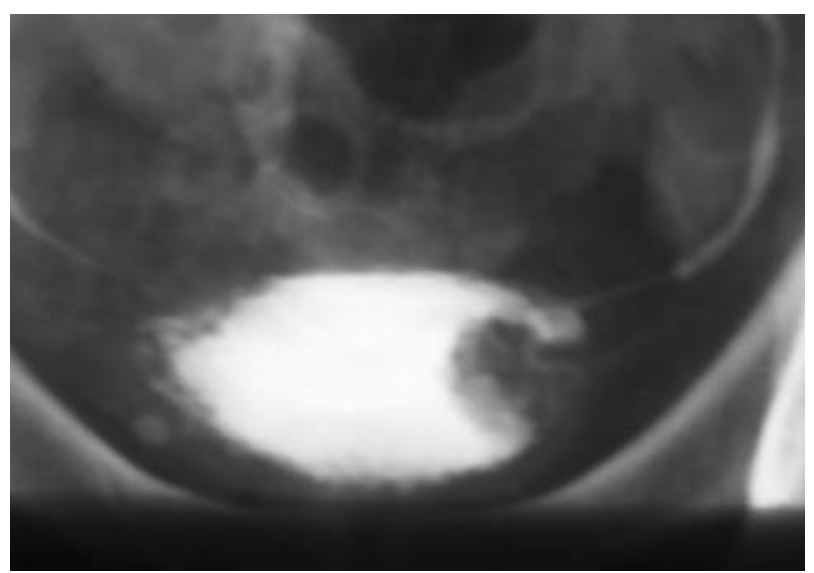

FIGURA 1. Cistograma. Defecto de replección en para lateral izquierda.

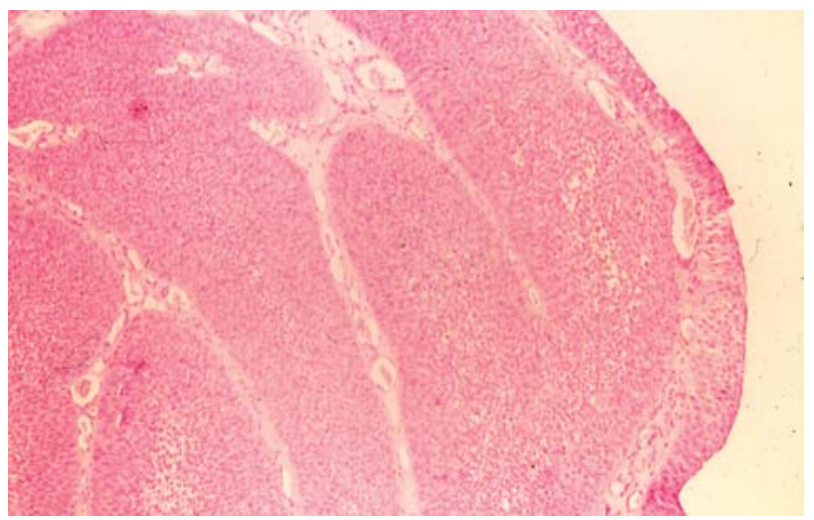

FIGURA 2. Anatomía patológica del papiloma invertido vesical.

Se realizó RTU de la lesión en enero de 2004 siendo el informe anatomopatológico de papiloma invertido que afecta orificio eyaculador y uretra prostática (Fig. 3). Además del papiloma invertido se observan focos de metaplasma escamosa que es frecuente en este tipo de tumores.

El control cistoscópico y citológico un año después ha sido normal.

\section{DISCUSION}

En 1927 Paschkis describe cuatro casos de "pólipos adenomatoides" de localización vesical. Histológicamente estas neoformaciones son idénticas a la lesión que en 1963 Potts y Hirts definen como papiloma invertido del tracto urinario ${ }^{1,3-6,9}$. Este tumor, con una apariencia histológica muy similar al papiloma invertido del tracto sinuna$\mathrm{sal}^{4}$, es muy infrecuente, constituyendo alrededor del $2,2 \%$ de todos los tumores del tracto urinario ${ }^{1-9,12,14}$.

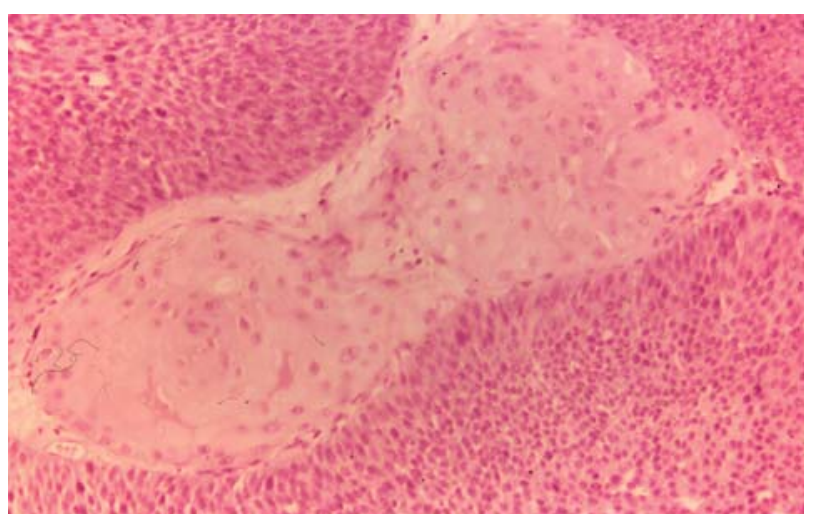

FIGURA 3. Anatomía patológica del papiloma invertido de uretra prostática. 
Hasta el momento se han descrito alrededor de $300 \operatorname{casos}^{9}$, en general publicados como notas clínicas o como una serie corta de pacientes ${ }^{4}$, destacando en la literatura castellana la serie de 31 pacientes de Núñez Mora et $\mathrm{al}^{7}$.

Habitualmente se da entre la $5^{\underline{a}}$ y $7^{\text {a }}$ década de la vida con predominio masculino entre 5-7/1 según series ${ }^{1-4,7,9}$.

La etiología de esta entidad es desconocida. Clásicamente se ha asociado a procesos inflamatorios crónicos pero se ha visto que este hecho sólo se da en el $27 \%$ de los casos, por lo que este mecanismo no estaría relacionado con el papiloma invertido $2,4,6$.

La forma de presentación suele ser la hematuria total, asociada o no a un sindrome obstructivo si la tumoración asienta en cuello vesical o en uretra ${ }^{1-4,7,9,12}$. Raramente se manifiesta como una infección urinaria ${ }^{7}$. También se han descrito casos asintomáticos en los que el diagnóstico ha sido casual ${ }^{1,3}$.

Macroscópicamente suele presentar un aspecto pediculado y polipoideo. En la mayoría de los casos se trata de una lesión única, aunque se

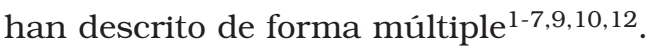

En 1975, Henderson propone los criterios aún utilizados hoy en día para el diagnóstico histológico $^{1-4,7,9,12}$ :

- Configuración invertida

- Capa superficial urotelial normal que penetra dentro del tumor, dándole un aspecto papilar.

- Células epiteliales uniformes con ausencia de mitosis.

- Formación de microquistes con material PAS + en su interior.

- Ausencia de metástasis.

- Presencia de metaplasia escamosa.

Kunze en 1983 describe dos tipos histológicos: trabecular y glandular. El tipo trabecular representaría una proliferación de las células basales del epitelio transicional mientras que el glandular correspondería al estadio final neoplásico de una transformación progresiva a partir de los islotes de Von Brunn, previo paso intermedio en cistitis quística y/o glandular 1,3-7,9,14.

El diagnóstico definitivo es siempre anatomopatológico, si bien pueden sernos útiles la ecografía y la UIV, siendo el método de elección la uretrocistoscopia ${ }^{1-4,7,9,11}$. La citología es de escasa rentabilidad, debido a la escasa descamación celular y a que las células obtenidas son iguales a las del urotelio normal ${ }^{3,9}$.

El potencial maligno y el valor pronóstico sigue siendo un tema de controversia ${ }^{1,3-5,7,8}$.

Las características histológicas, la baja tasa de recidivas, como ocurre en nuestro caso, descritas entre el 1 y $7 \%$ y el posible origen inflamatorio o metaplásico dada la similitud con la cistitis quística y/o glandular son datos a favor de considerar al papiloma invertido como una entidad de carácter benigno ${ }^{1-4,7-10,13-15}$.

Sin embargo existen datos a favor del potencial maligno de esta lesión. Se han descrito casos con asociación sincrónica o metacrónica con carcinoma urotelial $^{1,2,8}$. También se han observado anomalías nucleares con aumento de la actividad mitótica en algunos papilomas invertidos y de forma experimental se ha inducido un papiloma invertido de tipo glandular en ratas mediante el carcinógeno $\mathrm{N}$ (4-hidroxibutil)-nitrosamina ${ }^{1,4,12-14}$. Urakami, analiza el contenido de DNA y la inmunorreactividad al p53 observando que el papiloma invertido presenta una alta actividad proliferativa y mayor inmunorreactividad al p53 que los carcinomas transicionales superficiales, lo que le confiere susceptibilidad de transformación maligna ${ }^{3,15}$.

El tratamiento se reduce a la resección transuretral de la lesión con toma de biopsias múltiples randomizadas ${ }^{3,4,7}$.

Por último y en tanto no quede aclarado el potencial maligno se recomienda efectuar un seguimiento periódico similar al de un carcinoma vesical de bajo grado ${ }^{4,8,12,14}$.

\section{REFERENCIAS}

1. Pinos Paul MA, Lozano Uruñuela A, De Pablo Cárdenas A, Jiménez Aristu J, Jiménez Calvo A, Rivas Alonso A, et al. Papiloma invertido de uretra prostática. Actas Urol Esp 2000; 24(3):268-271.

2. Fernández Borrell A, Peinado Ibarra F, Gómez-Sancha F, et al. Cuatro nuevos casos de papiloma invertido urotelial. Actas Urol Esp 1998;22(7):620-623.

3. Ferrero Doria R, Guzmán Martínez Valls PL, Morga Egea JP, et al: Papiloma invertido: presentación de 5 casos y revisión de la literatura española. Actas Urol Esp 1998;22(2):131-136.

4. Witjes JA, Van Balken MR, Van De Kaa CA: The prognostic value of a primary inverted papilloma of the urinary tract. J Urol. 1997; 158: 1500-1505.

5. Viguri Diaz A, Córdoba Iturriagatoitia A, Millán JA, Rabasa Baraibar P. Papiloma invertido de uretra femenina. Arch Esp Urol 1995; 48(9): 954-956. 
6. Vesa Llanes J, Domingo Ferrerons R, Muntane Hombrados MJ, Nadal Vidal C. Papiloma invertido de uretra prostática. Consideraciones histopatogénicas. Arch Esp Urol 1994;47 (10):1022-1024.

7. García Rojo D, Pug Durán P, Abad Gairin C, et al. Papiloma invertido vesical. ¿ Se puede considerar una neoplasia de bajo grado de malignidad?. Arch Esp Urol 1993;46(3): 244-247.

8. Núñez Mora C, Ríos González E, García Mediero JM, et al. Valor pronóstico del papiloma invertido del tracto urinario inferior. Arch Esp Urol 2001;54(1):35-42.

9. Xambre L, Prisco R, Carreira F, Honavar M, Lages R. papilomas invertidos-casuística del servicio y revisión de la literatura. Actas Urol Esp 2003;27(8):605-610.

10. Rozanski T: Inverted papilloma: An unusual recurrent, multiple and multifocal lesion. J Urol 1996;155(4):1391

11. Pereira-Arias JG, Zabalza-Estevez I, Mariana-Fernandez $\mathrm{M}$, et al: Presentación sincrónica de papiloma invertido vesical y carcinoma transicional de pelvis renal. Arch Esp Urol 1995;48(10):1047-1050.
12. Mattelaer J, Leonard A, Goddeeris P, et al: Inverted papilloma of bladder: Clinical significance. Urology 1988;32: 192.

13. Valero JA, Redondo E, Jiménez C et al. Papiloma invertido transicional: expresión del antígeno Ki-67 como factor pronóstico. Arch Esp Urol 1995;48:887-892.

14. Risio M, Coverlizza S, Lasaponara F, Vercesi E. Invertid urothelial papilloma: a lesion with malignant potential. Eur Urol 1987;13:125.

15. Urakami S, Igawa M, Shirakawa H, Shiinah, Ishibe T: Biological characteristics of inverted papilloma of the urinary bladder. Br J Urol 1996;77:55-60.

Dra. B. Coronel Sánchez

Marqués de Valverde, $14-3^{\circ} \mathrm{A}$

12003 Castellón de la Plana

(Trabajo recibido el 30 de marzo 2005) 